\title{
Pomalidomide and lenalidomide regulate erythropoiesis and fetal hemoglobin production in human CD34+ cells
}

\author{
Laure A. Moutouh-de Parseval,,1,2 Dominique Verhelle, ${ }^{1}$ Emilia Glezer, ${ }^{1}$ Kristen Jensen-Pergakes, ${ }^{1}$ \\ Gregory D. Ferguson, ${ }^{1}$ Laura G. Corral, ${ }^{1}$ Christopher L. Morris, ${ }^{3}$ George Muller, ${ }^{2}$ \\ Helen Brady, ${ }^{1}$ and Kyle Chan ${ }^{1}$
}

${ }^{1}$ Celgene Corporation, San Diego, California, USA. ² Celgene Corporation, Summit, New Jersey, USA. ${ }^{3}$ Department of Pediatrics, Loma Linda University School of Medicine, Loma Linda, California, USA.

\begin{abstract}
Sickle-cell disease (SCD) and $\beta$ thalassemia constitute worldwide public health problems. New therapies, including hydroxyurea, have attempted to augment the synthesis of fetal hemoglobin ( $\mathrm{HbF})$ and improve current treatment. Lenalidomide and pomalidomide are members of a class of immunomodulators used as anticancer agents. Because clinical trials have demonstrated that lenalidomide reduces or eliminates the need for transfusions in some patients with disrupted blood cell production, we investigated the effects of lenalidomide and pomalidomide on erythropoiesis and hemoglobin synthesis. We used an in vitro erythropoiesis model derived from human $\mathrm{CD}_{34}{ }^{+}$progenitor cells from normal and SCD donors. We found that both compounds slowed erythroid maturation, increased proliferation of immature erythroid cells, and regulated hemoglobin transcription, resulting in potent induction of $\mathrm{HbF}$ without the cytotoxicity associated with other $\mathrm{HbF}$ inducers. When combined with hydroxyurea, pomalidomide and, to a lesser extent, lenalidomide were found to have synergistic effects on $\mathrm{HbF}$ upregulation. Our results elucidate what we believe to be a new mechanism of action of pomalidomide and lenalidomide and support the hypothesis that pomalidomide, used alone or in combination with hydroxyurea, may improve erythropoiesis and increase the ratio of fetal to adult hemoglobin. These findings support the evaluation of pomalidomide as an innovative new therapy for $\beta$-hemoglobinopathies.
\end{abstract}

\section{Introduction}

Sickle-cell disease (SCD) is a genetic hemoglobin ( $\mathrm{Hb})$ disorder that results in polymerization of sickle-cell $\mathrm{Hb}(\mathrm{HbS})$ upon deoxygenation, leading to a chronic cycle of ischemia/reperfusion vascular and tissue injury. $\beta$ Thalassemia is a hereditary anemia resulting from defects in $\mathrm{Hb}$ production due to a decrease in $\beta$-globin gene expression. The human $\beta$-globin locus is composed of the locus control region ( $\beta$-globin LCR), the $\varepsilon$-globin gene that is active in early fetal life, the $\gamma$-globin genes ( $G \gamma$ globin and $A \gamma$ globin), expressed mostly during fetal life, and the $\delta$ - and $\beta$-globin genes, which are activated late in fetal life, with the $\beta$-globin gene being most highly expressed in erythroid cells after birth and in adults. Based on the understanding of the pathophysiology of SCD and $\beta$ thalassemia, new experimental therapies attempt to augment the synthesis of fetal $\mathrm{Hb}(\mathrm{HbF})$ to limit the occurrence of vasoocclusive painful crises by inhibiting the formation of $\mathrm{HbS}$ polymers when the red cell is deoxygenated (1-3). The benefit of increasing $\mathrm{HbF}$ was first inferred from the reduced severity of disease observed in patients with SCD or $\beta$ thalassemia and persistence of higher concentration of $\mathrm{HbF}$ during adult life. This condition, deletional hereditary persistence of $\mathrm{HbF}(\mathrm{HPFH})$, is characterized by a pancellular synthesis of $\mathrm{HbF}$ with a milder sickling disorder

Nonstandard abbreviations used: $\mathrm{EC}_{50}$, median effective concentration; $\mathrm{Hb}$, hemoglobin; $\mathrm{HbA}$, adult $\mathrm{Hb}$; $\mathrm{HbF}$, fetal $\mathrm{Hb}$; HbS, sickle-cell Hb; HS, hypersensitive site(s); HU, hydroxyurea; LCR, locus control region; MDS, myelodysplastic syndrome; RNA pol II, RNA polymerase II; SCD, sickle-cell disease.

Conflict of interest: L.A. Moutouh-de Parseval, D. Verhelle, E. Glezer, K. JensenPergakes, G.D. Ferguson, L.G. Corral, G. Muller, H. Brady, and K. Chan have received income and research support from and have stock in Celgene Corporation. Citation for this article: J. Clin. Invest. 118:248-258 (2008). doi:10.1172/JCI32322. and reduced or eliminated transfusion requirement (4). Hydroxyurea $(\mathrm{HU})$ is currently the only drug approved by the FDA for the treatment of adult patients with moderate or severe $\operatorname{SCD}(5,6)$. Other inducers of $\mathrm{HbF}$ synthesis, such as butyrate, an inhibitor of histone deacetylases (7), and more recently decitabine (5-aza2 '-deoxycitidine), a DNA-demethylating drug, have also been shown to successfully induce $\mathrm{HbF}$ in patients with SCD (8-12). Even though HU ameliorates acute complications and prolongs life expectancy in some patients with SCD (13), many patients fail to achieve clinically significant increases of $\mathrm{HbF}(14)$. Moreover, to date, these $\mathrm{HbF}$ inducers have shown only modest response in a majority of $\beta$ thalassemia patients, most of whom continue to suffer from profound anemia (15-17).

Lenalidomide (CC-5013) and pomalidomide (CC-4047) are IMiD immunomodulatory drugs that have been described as having immunomodulatory properties and the ability to inhibit TNF- $\alpha$ production (18-20). Lenalidomide, a drug recently approved by the FDA under the commercial name of Revlimid, has shown reduction and elimination of the need for red blood-cell transfusions in some anemic myelodysplastic syndrome (MDS) patients $(21,22)$. Pomalidomide is currently under evaluation for the treatment of hematological cancers (23). To better understand how the use of these drugs leads to transfusion independence, we investigated lenalidomide and pomalidomide's effects on erythropoiesis and $\mathrm{Hb}$ synthesis using human $\mathrm{CD} 34^{+}$progenitor cells from normal and SCD patients as an in vitro erythropoiesis model.

The data presented here show that pomalidomide and lenalidomide can induce HbF expression in healthy and SCD CD34+derived erythrocytes by regulating the transcription of $\gamma$ - and $\beta$-globin genes. In addition, they have a synergistic effect, with HU 
A

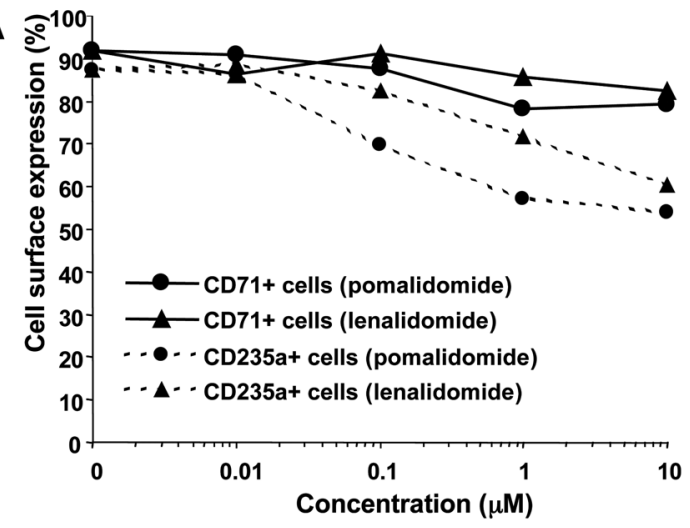

B

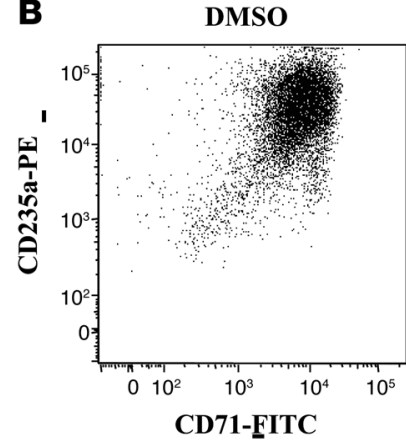

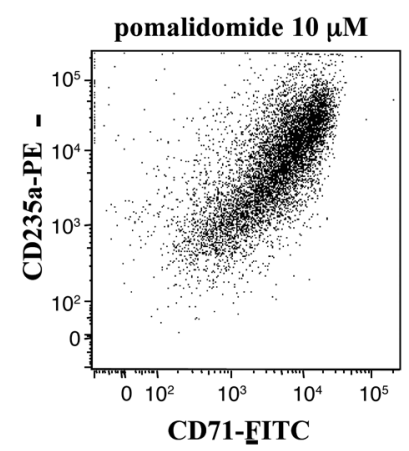

C
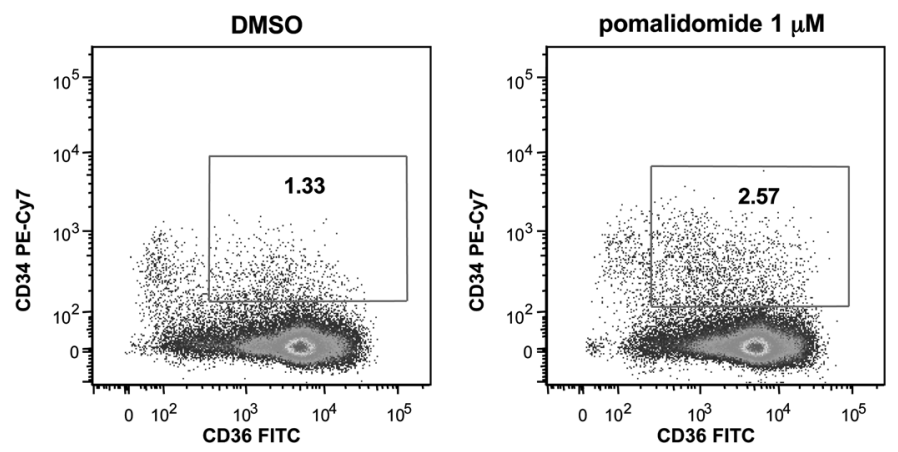

D
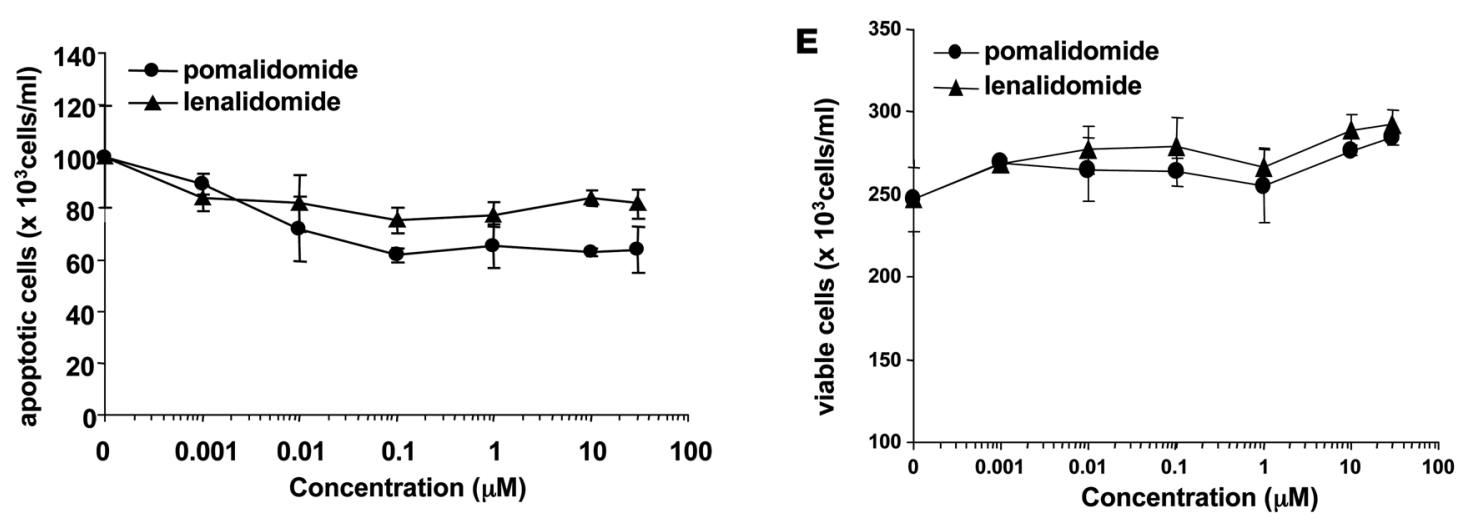

Figure 1

Pomalidomide and lenalidomide modulate erythroid differentiation. Expanded human $\mathrm{CD} 34^{+}$cells were differentiated to the erythroid lineage in the presence of increasing concentrations of pomalidomide and lenalidomide for 6 days. (A) Surface expression of erythroid markers glycophorin A (CD235a) and transferrin receptor (CD71) was monitored by flow cytometry. (B and C) $\mathrm{CD} 253 \mathrm{a}^{+} \mathrm{CD} 71^{+}$and $\mathrm{CD} 34^{+} \mathrm{CD} 36^{+}$cells were monitored by flow cytometry. ( $\mathbf{D}$ and $\mathbf{E}$ ) Apoptosis and viability of cells cultured with increasing concentration of pomalidomide and lenalidomide were measured using ViaCount. Results are representative of 3 independent experiments.

increasing $\mathrm{HbF}$ in cells from healthy and SCD donors, suggesting that pomalidomide may represent an interesting new therapy to study in patients with SCD and $\beta$-hemoglobinopathies.

\section{Results}

Pomalidomide and lenalidomide modulate human erythroid differentiation. We studied the effects of pomalidomide and lenalidomide on erythropoiesis in a 2-phase erythroid differentiation liquid culture assay using human $\mathrm{BM} \mathrm{CD} 34^{+}$progenitor cells and monitored the expression of erythroid markers thrombospondin receptor (CD36), glycophorin A (CD235a) and transferring receptor (CD71) at different stages of erythroid differentiation. After 6 days, the majority of the cells $(\geq 80 \%)$ cultured in the presence of vehicle control became erythroid, as characterized by the expression of cell-surface markers CD235a and CD71 (24) (Figure 1A). CD235a, a late marker of erythroid differentiation, was decreased with pomalidomide treatment and to a lower extent with lenalidomide (Figure 1, A and B). In contrast, CD71, an early marker of erythroid differentiation, was maintained at a high level (Figure 1, A and B). Moreover, we observed a 2-fold increase of the $\mathrm{CD} 34^{+} \mathrm{CD} 36^{+}$immature erythroid progenitors when cells were cultured with $1 \mu \mathrm{M}$ of pomalidomide (Figure 1C). Differentiation is often associated with a concomitant increase of apoptosis; similarly, it has been shown that the interaction between immature and mature erythroblasts contributes to 

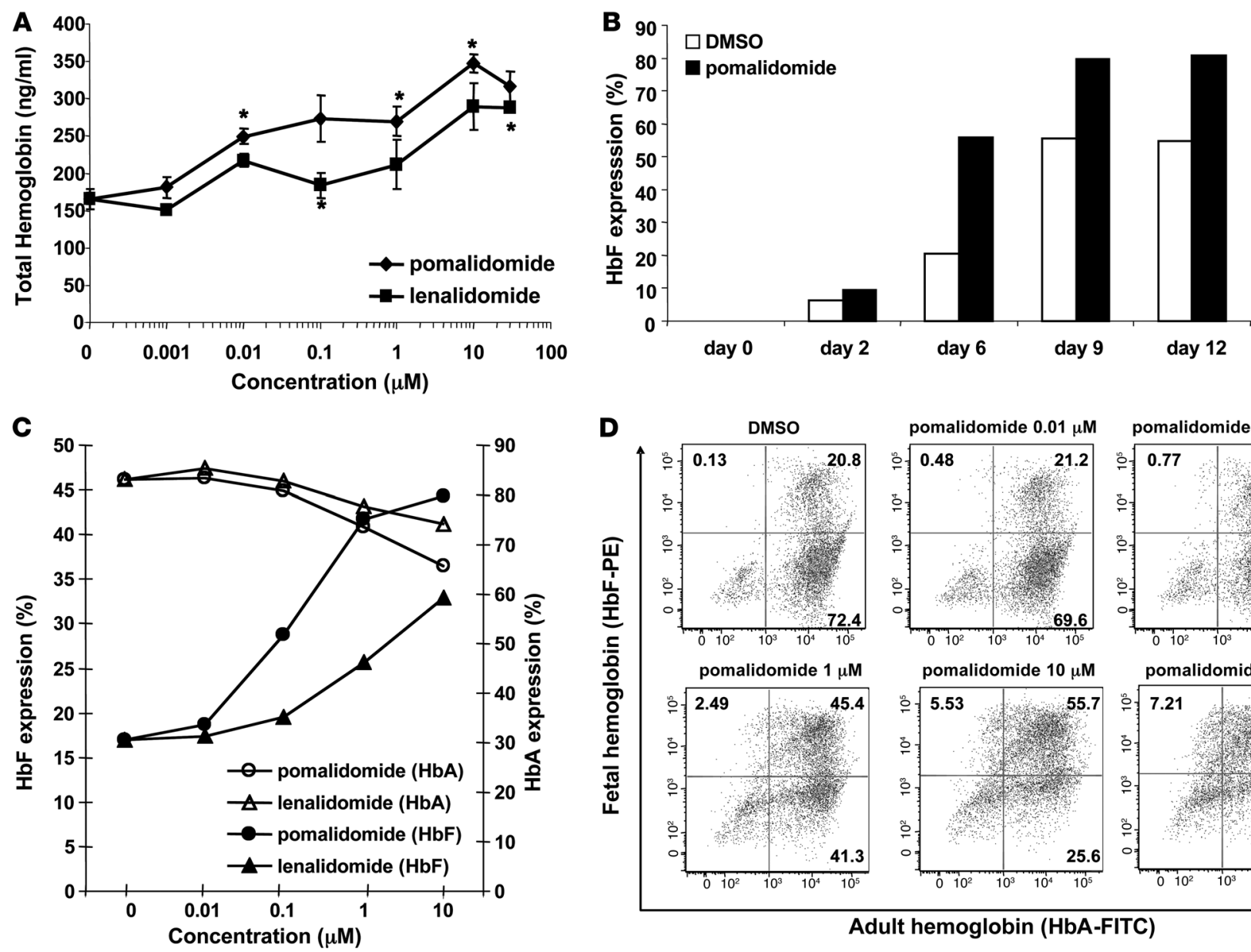

D

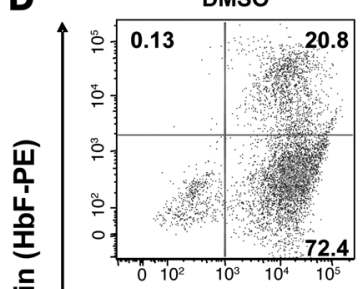

pomalidomide $1 \mu \mathrm{M}$

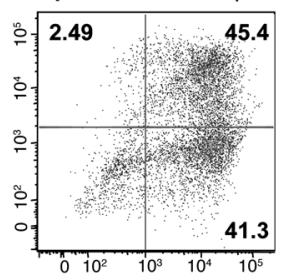

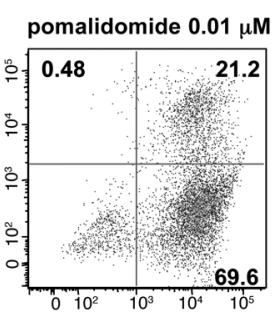

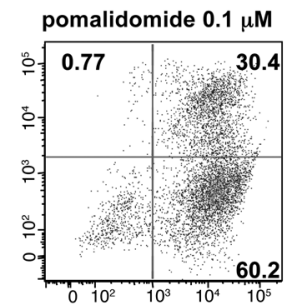

pomalidomide $10 \mu \mathrm{M}$
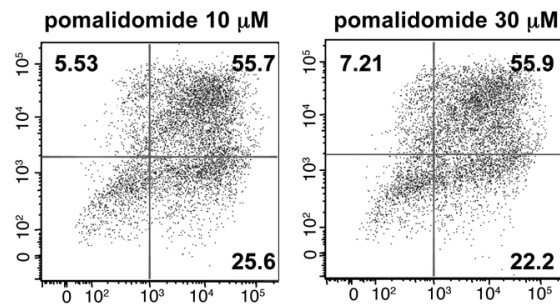

Adult hemoglobin (HbA-FITC)

Figure 2

Pomalidomide and lenalidomide increase HbF production in erythroid cells. (A) Quantification of total Hb production was done by ELISA assay after 6 days of erythroid differentiation. Values represent mean \pm SEM $(n=3)$. (B) Expression of HbF was monitored by flow cytometry after $2,6,9$, and 12 days of cell differentiation with $1 \mu \mathrm{M}$ pomalidomide. (C and $\mathbf{D}) \mathrm{HbF}$ and $\mathrm{HbA}$ were monitored after 6 days of cell differentiation, with increasing concentrations of pomalidomide. Scatter plots illustrate the distribution of $\mathrm{HbF}^{+}$and $\mathrm{HbA}^{+}$erythroid cells. The experiments were repeated on samples from at least 2 different donors with similar results. ${ }^{*} P<0.05$.

inducing apoptosis during erythroid differentiation, where mature erythroblasts can activate programmed cell death of more immature ones (25-27). We observed a decrease in cell apoptosis with pomalidomide and lenalidomide (Figure 1D), as we would anticipate if differentiation were slowed down. This decrease in apoptosis was not associated with a decrease in cell number (Figure 1E).

Pomalidomide and lenalidomide are potent inducers of $\mathrm{HbF}$ during erythroid differentiation of human $\mathrm{CD} 34^{+}$progenitors. After the induction of erythroid differentiation for 6 days, total $\mathrm{Hb}$ levels were determined by ELISA assay. Figure $2 \mathrm{~A}$ shows that pomalidomide and lenalidomide significantly increased in a dose-dependent manner $\mathrm{Hb}$ expression compared with vehicle control. We further investigated these compound effects on $\mathrm{Hb}$ production by monitoring the percentage of expression of fetal $\mathrm{Hb}(\mathrm{HbF})$ and adult $\mathrm{Hb}$ $(\mathrm{HbA})$ in erythroid-differentiated cells (F cells) using flow cytometry. Pomalidomide and lenalidomide were able to significantly increase $\mathrm{HbF}$ expression in a dose- and time-dependent manner during erythropoiesis. Pomalidomide and lenalidomide at $10 \mu \mathrm{M}$ increased 3-fold and 2-fold the percentage of $\mathrm{HbF}$-containing cells as compared with vehicle control, respectively (Figure 2C). $\mathrm{HbF}$ upregulation induced by pomalidomide was observed as early as 2 days and increased in a time-dependent manner. After 9 days, $\mathrm{HbF}$ expression was not further increased but sustained (Figure $2 \mathrm{~B}$ ). Based on the $\mathrm{HbF}$ median effective concentration $\left(\mathrm{EC}_{50}\right)$ values, defined as the log concentration of the drug that induces $50 \%$ of the maximal response, we found that pomalidomide is a more potent inducer of $\mathrm{HbF}$ than lenalidomide $(0.08 \mu \mathrm{M}$ vs. $1.9 \mu \mathrm{M}$, mean obtained from 22 and 11 donors, respectively; data not shown). The increase in $\mathrm{HbF}$ expression was associated with a slight decrease in $\mathrm{HbA}$ expression (Figure 2C), resulting in an increase of the $\mathrm{HbF} / \mathrm{HbA}$ ratio. Figure $2 \mathrm{D}$ shows the distribution of $\mathrm{HbF}$ and $\mathrm{HbA}$ in erythroid cells, with both an increase of $\mathrm{HbA}^{+} \mathrm{HbF}^{+}$ double-positive population (55.9\% with $30 \mu \mathrm{M}$ of pomalidomide compared with $20.8 \%$ with control) and $\mathrm{HbA}^{-} \mathrm{HbF}^{+}$single-positive population $(7.21 \%$ with $30 \mu \mathrm{M}$ pomalidomide compared with $0.13 \%$ with control). These results indicate that the number of F cells and their $\mathrm{HbF}$ content increase when erythroid cells are differentiated in the presence of increasing concentrations of pomalidomide.

We next measured the levels of $\gamma$ - and $\beta$-globin mRNA at different stages of erythroid differentiation (days 2, 3, 6, 9, and 12) using 

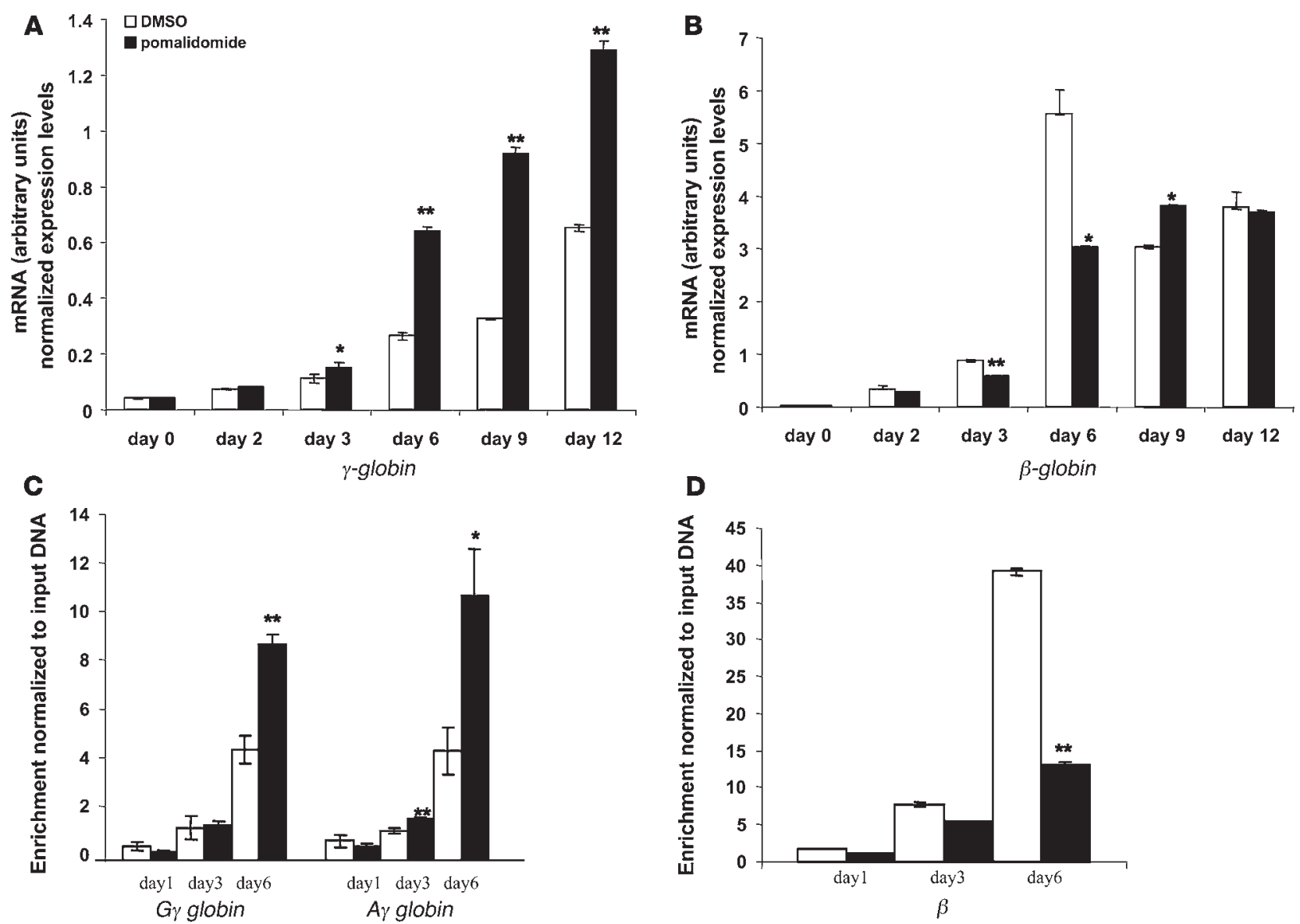

\section{Figure 3}

Pomalidomide modulates the transcription of $\beta$-globin locus genes. (A and B) Expanded CD $34^{+}$cells were differentiated to the erythroid lineage for 12 days in the presence of $1 \mu \mathrm{M}$ pomalidomide. Cells were harvested at different times of erythroid differentiation, total RNA was extracted, and $\gamma$-globin (A) and $\beta$-globin (B) expression were monitored by real-time PCR analysis using Taqman PCR probes for $\gamma$-globin and $\beta$-globin,

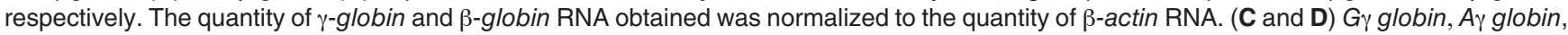
and $\beta$ levels of transcription were assayed by ChIP. After 1, 3, or 6 days of cell differentiation in the presence of vehicle control or pomalidomide

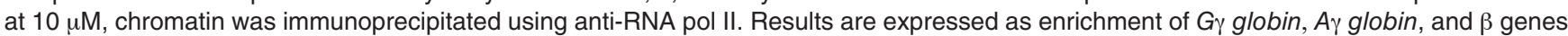
relative to the input DNA and are normalized to the results obtained with GAPDH-positive control. Values represent mean \pm SEM $(n=3)$ and are representative of 2 independent experiments. ${ }^{*} P<0.05 ;{ }^{*} P<0.001$.

quantitative real-time PCR to determine whether the regulation of $\mathrm{HbF}$ and $\mathrm{HbA}$ expression with pomalidomide was correlated with the increase of mRNA levels of $\gamma$ - and $\beta$-globin. As shown in Figure 3, $A$ and $B$, a time-dependent increase of $\gamma$-and $\beta$-globin mRNA levels was found with the vehicle control, which correlates with the erythrocyte differentiation. In addition, we found that pomalidomide at $1 \mu \mathrm{M}$ enhanced $\gamma$-globin upregulation while decreasing $\beta$-globin expression. After 6 days, pomalidomide increased $\gamma$-globin mRNA levels 2 -fold and decreased $\beta$-globin levels 2 -fold (Figure 3, A and B).

Pomalidomide modulates the transcription of $\gamma$ - and $\beta$-globin genes. To determine whether the regulation of globin mRNA levels is transcription dependent, we analyzed the transcription rate of $\gamma$-and $\beta$-globin genes during the course of erythroid differentiation by measuring the occupancy of RNA polymerase II (RNA pol II) on the respective genes. Sandoval et al. have shown that ChIP using the RNA pol II was an effective method to measure the actual transcription rate of the gene of interest (28). RNA pol II ChIP shows an enrichment of G $\gamma$ globin and A $\gamma$ globin genes during erythrocyte differentiation, with a stronger effect with pomalidomide (2.5-fold increase for both Gy globin and A y globin after 6 days of differentiation) compared with the vehicle control (Figure 3C). As anticipated, pomalidomide significantly decreased in a time-dependent manner $\beta$-globin gene transcription (3-fold decrease compared with vehicle control after 6 days of cell differentiation) (Figure 3D). These results indicate that pomalidomide modulates the transcription rate of $\gamma$-and $\beta$-globin genes observed during erythrocyte differentiation.

The regulation of $\gamma$-and $\beta$-globin by pomalidomide is correlated with the modification of epigenetic marks associated to $\beta$-globin locus. It has been shown that the switch between $\varepsilon$-, $\gamma$-, and $\beta$-globin expression during embryo, fetal, and adult life is highly regulated by chromatin remodeling (29-31). Because the increase of acetylation of histone $\mathrm{H} 3$ on lysine 9 and 14 has been described to be associated with the increase of transcription, the modification of histone acetylation was studied by analyzing the presence of histone $\mathrm{H} 3$ acetylated specifically on lysines 9 and 14 on the globin promoters ( $G \gamma$ globin, $A \gamma$ globin, and $\beta$ genes) and on the hypersensitive sites (HS), HS2 and $H S 3$, of the LCR by ChIP. We found a modulation of histone $\mathrm{H} 3$ acetylation on the promoters of $G \gamma$ globin, $A \gamma$ globin, $\beta$, and the 2 

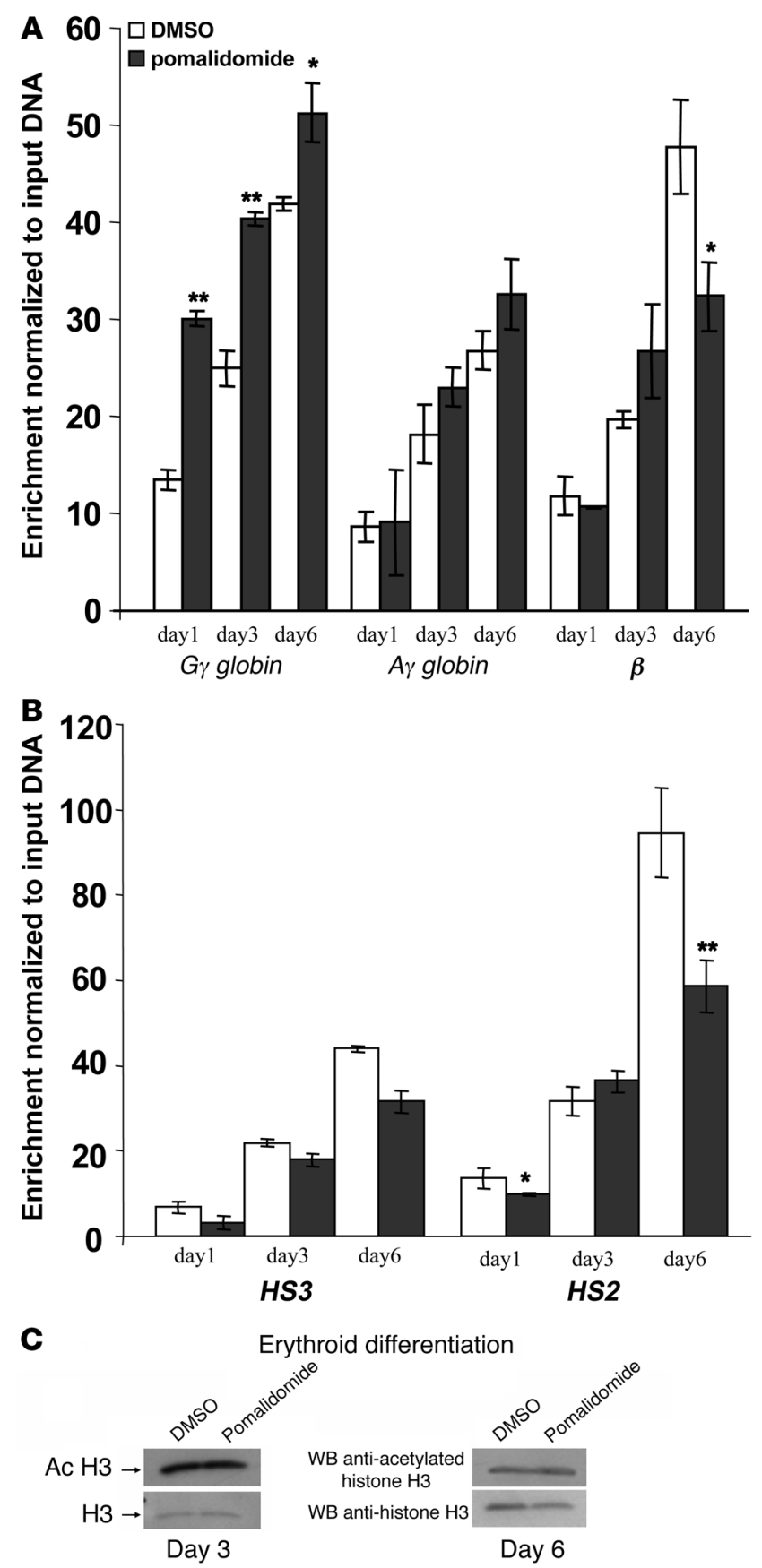

HS analyzed when cells were differentiated toward erythrocytes in the presence of vehicle control (Figure 4, A and B). In the presence of pomalidomide, the acetylation of $\mathrm{H} 3$ was increased on $\mathrm{G} \gamma$ globin and $A \gamma$ globin promoters and decreased on $\beta$ promoter compared with vehicle control (Figure 4A). These results correlated well with those obtained for the transcription rate (Figure 3, B and C). The increase of acetylated $\mathrm{H} 3$ on HS2 and HS3 during cell differentiation was inhibited in the presence of pomalidomide (Figure 4B). These results suggest that pomalidomide affects the epigenetic marks in $\gamma$ - and $\beta$-globin promoters as well as in the LCR. To determine whether pomalidomide modulates the level of acetylated histone $\mathrm{H} 3$ at the global level during the erythroid differentiation,

\section{Figure 4}

Pomalidomide modulates histone $\mathrm{H} 3$ acetylation on $\beta$-globin locus during erythroid differentiation of CD34+ cells. (A and B) CD34+ cells differentiated to the erythroid lineage in the presence of vehicle control or pomalidomide at $10 \mu \mathrm{M}$ for 1 day, 3 days, or 6 days were subjected to ChIP using an anti-acetyl histone $\mathrm{H} 3 \mathrm{~K} 9$ and $\mathrm{K} 14$ antibody and

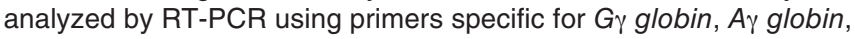
and $\beta$ promoters $(\mathbf{A})$ and for $L C R, H S 2$, and $H S 3(\mathbf{B})$. Results are expressed as enrichment of genes of interest relative to the input DNA and are normalized to the results obtained with GAPDH-positive control. Values represent mean \pm SEM $(n=3)$ and are representative of 2 independent experiments. (C) Acetylation of histone $\mathrm{H} 3$ on $\mathrm{K} 9$ and K14 was monitored by Western blot after 3 and 6 days of erythroid differentiation in the presence of vehicle control or pomalidomide at $10 \mu$ M. ${ }^{*} P<0.05 ;{ }^{* *} P<0.001$.

purified histones from cells differentiated with vehicle control and pomalidomide for 3 and 6 days were analyzed by Western blot using anti-acetylated $\mathrm{H} 3$ antibody. As shown in Figure 4C, no significant difference between the compound and the vehicle control was detected after 3 and 6 days, indicating that pomalidomide only affects the acetylation of histone $\mathrm{H} 3$ on specific genes and does not modify global histone acetylation.

Pomalidomide and lenalidomide are better $\mathrm{HbF}$ inducers than $\mathrm{HU}$ and butyrate in erythroid cells from healthy donors. To evaluate the efficacy of pomalidomide and lenalidomide in inducing $\mathrm{HbF}$, we compared our compounds to other inducers of $\mathrm{HbF}$ that have been used in patients with SCD (Figure 5). The ex vivo evaluation of HbF expression by flow cytometry in erythroid cells after 6 days of differentiation with increasing concentrations of $\mathrm{HU}$ and butyrate shows that both drugs are less efficient inducers of $\mathrm{HbF}$ expression than pomalidomide and lenalidomide (Figure 5A). In the donor tested, the $\mathrm{EC}_{50}$ levels of pomalidomide and lenalidomide were $0.08 \mu \mathrm{M}$ and $4 \mu \mathrm{M}$ compared with more than $30 \mu \mathrm{M}$ and $150 \mu \mathrm{M}$ for HU and butyrate $\mathrm{EC}_{50}$, respectively. In all the donors tested, pomalidomide and lenalidomide increased in a dose-dependent manner the percentage of erythroid cells expressing $\mathrm{HbF}$, but unlike $\mathrm{HU}$ and butyrate, cell viability was not affected (Figure 5B).

Pomalidomide and lenalidomide are synergistic with $\mathrm{HU}$ in increasing $\mathrm{HbF}$ expression during erythroid differentiation. Because both $\mathrm{HU}$ and pomalidomide increase $\mathrm{HbF}$, we sought to assess whether a combined treatment would show additive or synergistic effects on our erythroid cell model. We found that the combination of $\mathrm{HU}$ and pomalidomide was synergistic in inducing $\mathrm{HbF}$ expression when concentrations of pomalidomide of $1 \mu \mathrm{M}$ or $10 \mu \mathrm{M}$ were combined to HU $10 \mu \mathrm{M}$ (Figure 6, A and B) while only additive when lower concentrations of pomalidomide $(0.1 \mu \mathrm{M})$ were used. To a lesser extent, we observed similar results with lenalidomide (Figure 6A). As shown in Figure 6B, the percentage of $\mathrm{HbF}$ expression and the MFI increased from $12.5 \%(\mathrm{MFI}=6355)$ for $\mathrm{HU}$ alone to $31.7 \%$ $(\mathrm{MFI}=9049)$ for $\mathrm{HU}$ plus lenalidomide and $54.7 \%(\mathrm{MFI}=9717)$ for HU plus pomalidomide. This synergistic effect of pomalidomide and HU in vitro in 2 different donors provides further rationale to explore their use for combination therapy.

Pomalidomide and lenalidomide induce $\mathrm{HbF}$ in erythroid cells from $S C D$ patients. To confirm that pomalidomide is able to induce $\mathrm{HbF}$ in erythroid cells from SCD patients, we studied its effect using $\mathrm{CD} 34^{+}$cells isolated from whole blood from 8 SCD donors. We found that pomalidomide and lenalidomide increased $\mathrm{HbF}$ expression in all 8 and 6 patient samples tested, respectively (Table 1). 
A

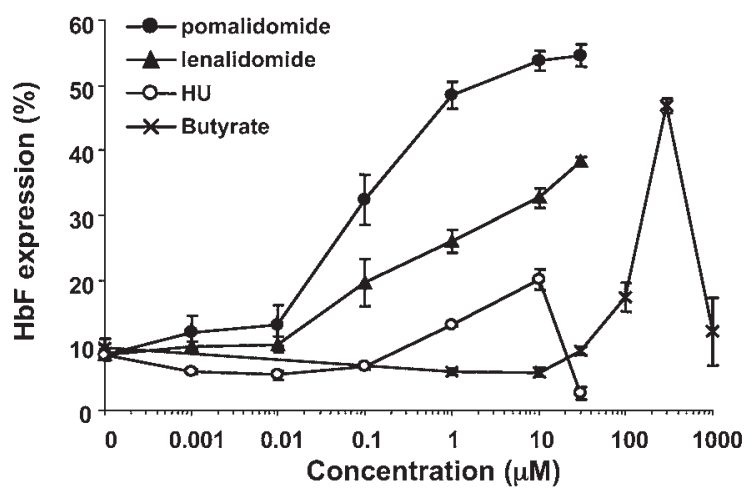

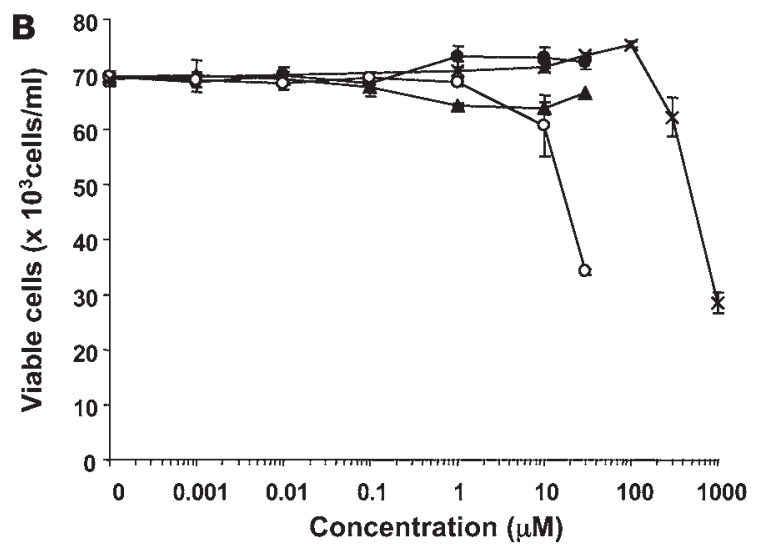

Figure 5

Pomalidomide and lenalidomide are more potent than $\mathrm{HU}$ and butyrate for inducing $\mathrm{HbF}$ expression in CD34-derived erythrocytes. (A) $\mathrm{HbF}$ expression was monitored by flow cytometry after 6 days of erythroid differentiation, with increasing concentration of pomalidomide, lenalidomide, HU, and butyrate. (B) Cell viability was monitored after 6 days by forward- and side-scattering intensity in dot plots. Results represent mean \pm SEM $(n=3)$ and are representative of 3 independent experiments.

Similar to the results obtained with cells from healthy donors (Figure 6A), in the 8 samples tested, pomalidomide was a more efficient inducer of $\mathrm{HbF}$ than $\mathrm{HU}$ and equivalent or more potent than butyrate for the 6 donors tested. Pomalidomide induced $\mathrm{HbF}$ expression in a dose-dependent manner with a detectable increase at $0.001 \mu \mathrm{M}$ of pomalidomide (Figure $7 \mathrm{~A}$ ). As demonstrated for normal cells, pomalidomide showed synergistic effects with HU in inducing $\mathrm{HbF}$ expression in $\mathrm{CD}_{3} 4^{+}$cells obtained from SCD patients differentiated toward erythrocytes (Figure 7B). The percentage of erythroid cells expressing $\mathrm{HbF}$ increased from $44.7 \%$ (pomalidomide, $0.1 \mu \mathrm{M}$, alone) to $64 \%$ (pomalidomide, $0.1 \mu \mathrm{M}$, combined with $\mathrm{HU}, 10 \mu \mathrm{M}$ ), while single treatment with $10 \mu \mathrm{M}$ $\mathrm{HU}$ increased this percentage only slightly $(22.3 \%$ in comparison with $18.6 \%$ in the vehicle control). Taken together, these results strongly suggest that pomalidomide is an $\mathrm{HbF}$ inducer, mechanistically different from HU and butyrate, and could offer additional benefits to patients with SCD and $\beta$ thalassemia.

\section{Discussion}

This study demonstrates that, in addition to their known immunomodulatory properties $(18,19)$, pomalidomide and lenalidomide, 2 distinct IMiD immunomodulatory drugs, are potent regulators of erythropoiesis and $\mathrm{Hb}$ synthesis during erythroid differentiation (in vitro) with the ability to reactivate globin genes normally silenced during development, such as $\gamma$-globin. This property provides insights into the mechanism by which lenalidomide can improve $\mathrm{Hb}$ levels in patients with MDS and multiple myeloma and suggests that pomalidomide may be an innovative new therapy for SCD and $\beta$ thalassemia.

The clinical outcome of SCD patients has improved considerably since the approval of HU for the treatment of SCD in 1998 (5). However, despite improvements in morbidity and mortality, $\mathrm{HU}$ is not beneficial for all patients $(13,14)$. Survival rates in the Multicenter Study of Hydroxyurea in Sickle Cell Anemia (MSH) trial were strongly correlated with the increase in $\mathrm{HbF}$ level (13, 14), confirming the importance of increasing and maintaining $\mathrm{HbF}$ levels for the treatment of SCD. The induction of $\mathrm{HbF}$ by HU is not entirely understood but is believed to be through a combination of its cytotoxicity, which causes erythroid regeneration, and a metabolic mechanism that leads to NO release (32). Beyond its effect on HbF, HU may have other beneficial effects in SCD and lessen the chance of vasoocclusive events by reducing the number of leukocytes and affecting their activation (33).

We sought to determine whether pomalidomide (currently under evaluation for the treatment of hematological cancers) and lenalidomide (Revlimid) could regulate erythropoiesis and $\mathrm{Hb}$ synthesis using an in vitro liquid culture model to differentiate human erythroid progenitors from BM or peripheral blood CD $34^{+}$ cells. As previously described in the literature (34-38), this model produces large cultures of relatively pure and synchronized erythroid cell populations derived either from normal donors (BM CD $34^{+}$cells) or patients with SCD (whole-blood CD $34^{+}$cells) and allowed us to monitor the stage of erythroid differentiation and $\mathrm{Hb}$ production at multiple time points.

Our results show that pomalidomide is a potent inducer of $\mathrm{HbF}$ expression and modulates erythroid differentiation during the specific commitment of $\mathrm{CD} 34^{+}$progenitor cells toward the erythroid lineage. We observed that when erythroid progenitors were cultured with pomalidomide or lenalidomide, the level of glycophorin A, a marker that is expressed later during erythroid maturation, was diminished in comparison with vehicle control. By monitoring markers of various cell lineages, we discovered that the decrease in glycophorin A expression was not due to a shift to another lineage (data not shown) but was the result of an increase in the less mature erythroid population. Modulation of erythropoiesis by pomalidomide and lenalidomide was associated with an increase in both $\mathrm{HbF}$ and total $\mathrm{Hb}$ production, suggesting that this may be one mechanism by which lenalidomide increased $\mathrm{Hb}$ levels and abolished transfusion dependency in patients with $\operatorname{MDS}(21,22,39)$.

We observed an inverse relationship between $\mathrm{HbF}$ and $\mathrm{HbA}$ accumulation in erythroid cells in the in vitro model. Increases in the percentage of F cells ranged from 2- to 3-fold among the donors with a homogeneous distribution of $\mathrm{HbF}$ and an increase of $\mathrm{HbF} / \mathrm{HbA}$ ratio that, in the context of $\mathrm{SCD}$, should prevent the formation of the HbS polymer responsible for the sickling of erythrocytes (40).

Compared with HU, 5-azacytidine, and butyrate, pomalidomide is a strong inducer of $\mathrm{HbF}$, producing twice the expression of $\mathrm{HbF}$ in our in vitro model. Unlike these other HbF inducers, pomalido- 
A

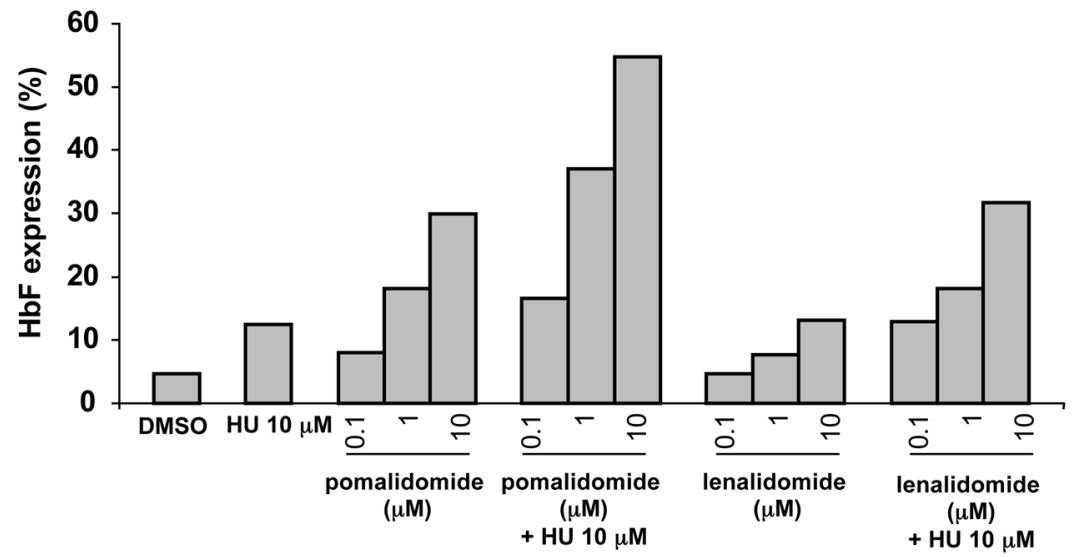

B

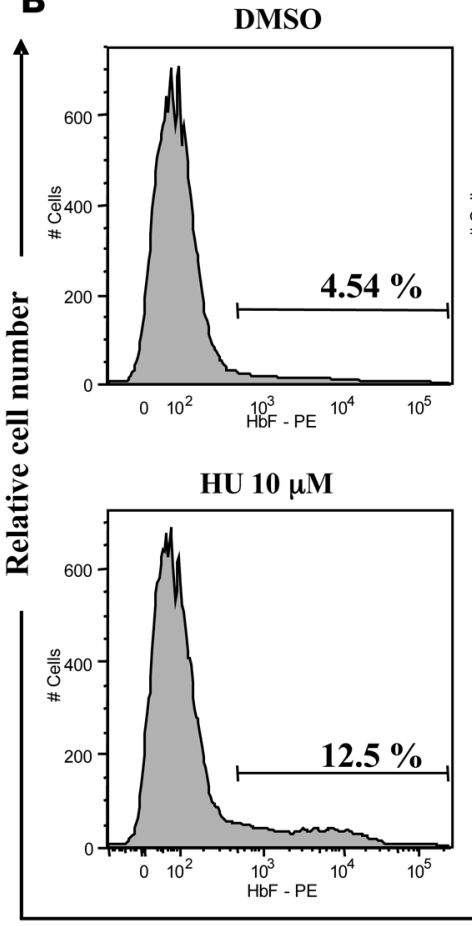

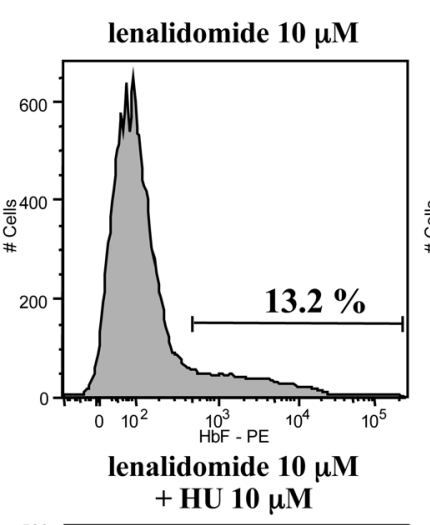

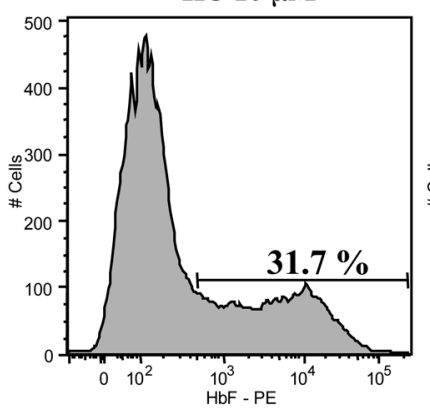

pomalidomide $10 \mu \mathrm{M}$

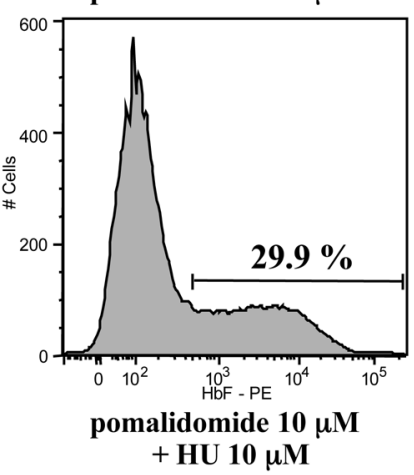

+ HU $10 \mu \mathrm{M}$

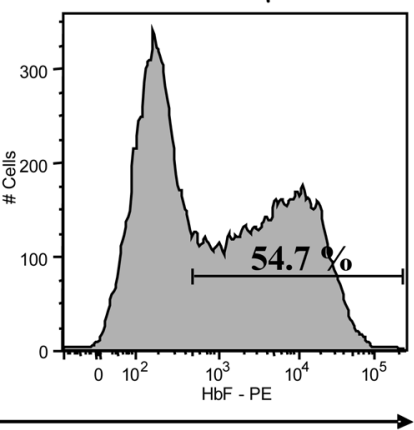

\section{Figure 6}

$\mathrm{HU}$ is synergistic with pomalidomide and lenalidomide in increasing $\mathrm{HbF}$ expression during erythroid differentiation. CD $34^{+}$cells were differentiated toward erythroid lineage in the presence of increasing concentrations of pomalidomide, lenalidomide, and $\mathrm{HU}$ at $10 \mu \mathrm{M}$ alone or in combination. After 6 days, HbF expression was evaluated by flow cytometry. (A) Histograms of the percentage of cells expressing $\mathrm{HbF}$ in response to single or combination treatments are represented. (B) Histograms represent the MFI relative to the cell number. The experiments were repeated on samples from at least 2 different donors with similar results.

HbF-PE (fluorescence intensity)

mide and lenalidomide are not cytotoxic to the erythroid progenitors and actually reduced the number of erythroid-differentiated cells undergoing apoptosis. Verhelle et al. (41) also reported that pomalidomide and lenalidomide induce expansion of $\mathrm{CD} 34^{+}$cells with no reduction in total cell numbers, further supporting the concept that pomalidomide can expand the immature erythroid population and slow down the rate of cellular differentiation. The combination of stimulating erythropoiesis and increasing erythroid progenitor survival makes these drugs ideal candidates for the treatment of ineffective erythropoiesis observed in diseases like MDS and $\beta$-hemoglobinopathies. Pomalidomide is a more potent inducer of $\mathrm{HbF}$ expression $\left(\mathrm{EC}_{50}=80 \mathrm{nM}\right)$ than lenalidomide $\left(\mathrm{EC}_{50}=1.9 \mu \mathrm{M}\right)$. For both drugs, the concentration required to increase $\mathrm{HbF}$ expression by 2 -fold corresponds to clinically achievable levels based upon plasma levels obtained after a single oral dose of pomalidomide and lenalidomide in healthy volunteers (42) and to well-tolerated doses in clinical studies. In addition, the combination of either pomalidomide or lenalidomide with $\mathrm{HU}$ is synergistic, supporting the notion that pomalidomide, either as a single agent or in combination with $\mathrm{HU}$, may be efficacious in patients that do not respond to HU. This synergistic effect of certain IMiD immunomodulatory drugs with $\mathrm{HU}$ and the nontoxic effect of pomalidomide on erythroid progenitors are particularly relevant to the problem of $\mathrm{HbF}$ production in $\beta$ thalassemia where $\mathrm{HU}$, butyrate, and erythropoietin monotherapies have failed (43). Moreover, the ability of pomalidomide to increase the pool of immature erythroid progenitors is significant for $\beta$ thalassemia treatment because one important factor in the anemia of $\beta$ thalassemia is ineffective erythropoiesis, resulting in a large-scale destruction of red-cell precursors in the BM (44).

To further define the mechanism of action by which our drugs induce $\mathrm{HbF}$ expression, we studied the effect of pomalidomide on the regulation of $\beta$-globin genes. Considerable advances have been made in the understanding of globin gene switching during 
Table 1

Percentage of $\mathrm{HbF}^{+}$cells in response to $\mathrm{HbF}$ inducers in $\mathrm{CD}_{4}+$-derived erythrocytes from 8 SCD patients

\begin{tabular}{|c|c|c|c|c|c|}
\hline & \multicolumn{5}{|c|}{$\% \mathrm{HbF}^{+}$cells } \\
\hline & DMSO & $\begin{array}{c}\text { Pomalidomide } \\
\text { (10 } \mu \mathrm{M})\end{array}$ & $\begin{array}{c}\text { Lenalidomide } \\
\text { (10 } \mu \mathrm{M})\end{array}$ & $\begin{array}{c}\text { HU } \\
(10 \mu \mathrm{M})\end{array}$ & $\begin{array}{c}\text { Na butyrate } \\
(100 \mu \mathrm{M})\end{array}$ \\
\hline SCD no. 1 & 31 & 66.4 & ND & 41.3 & ND \\
\hline SCD no. 2 & 18.6 & 56.8 & ND & 22.2 & ND \\
\hline SCD no. 4 & 42 & 65.1 & 58.1 & 60.1 & 65.5 \\
\hline SCD no. 5 & 26.6 & 51.1 & 39.6 & 42.9 & 57.0 \\
\hline SCD no. 6 & 32.0 & 52.4 & 48.1 & 40.0 & 36.9 \\
\hline SCD no. 7 & 21.6 & 49.6 & 38.8 & 43.8 & 0.67 \\
\hline SCD no. 8 & 24.7 & 55.3 & 43.9 & 49.2 & 23.6 \\
\hline SCD no. 9 & 25.7 & 61.6 & 48.65 & 50.1 & 23.1 \\
\hline Mean & 27.8 & 57.3 & 46.2 & 43.7 & 41.2 \\
\hline SD & 7.3 & 6.4 & 7.1 & 10.8 & 19.4 \\
\hline
\end{tabular}

CD34+ cells were isolated from PBMCs of 8 SCD patients, expanded for 6 days, and differentiated to the erythroid lineage in the presence of pomalidomide, lenalidomide, $\mathrm{HU}$, and butyrate. Values represent the percentage of $\mathrm{HbF}^{+}$cells monitored by flow cytometry. ND, not determined.

ing to the $\gamma$-globin and $\beta$-globin gene promoters respectively (Figure $3, \mathrm{C}$ and $\mathrm{D}$ ). Pomalidomide did not increase $\alpha$-globin gene expression (data not shown). This finding is of interest in $\beta$ thalassemia, as an increase in $\alpha$-globin gene expression could counteract the increase in $\gamma$-globin gene expression and reduce the beneficial effect of the increase of $\gamma$-globin expression on chain imbalance $(49,50)$. Coinheritance of $\alpha$ thalassemia mutations in patients with $\beta$ thalassemia has been associated with a milder clinical course because of a less severe inbalance in $\alpha-\beta$ chain (51).

Histone deacetylase inhibitors like sodium butyrate have been shown to induce $\mathrm{HbF}$ synthesis in vitro and in humans $(8,17,52-54)$, in part through their ability to induce histone hyperacetylation. We hypothesized that pomalidomide could regulate $\mathrm{HbF}$ by modifying chromatin structure. Indeed, pomalidomide selectively increased by more than 2 -fold the level of histone $\mathrm{H} 3$ acetylated on $\mathrm{K} 9$ and

development and erythroid differentiation (9), in which transcription factors and chromatin-remodeling complexes play an important role in the control of globin genes (45-47). The $\beta$-globin LCR upstream of the globin structural genes ( $\varepsilon, G \gamma$ globin, A $\gamma$ globin, $\delta$, and $\beta$ ) that consists of 5 DNAse 1 HS is needed for globin gene transcription. During differentiation, the promoters of human $\beta$-globin genes undergo an extensive chromatin remodeling accompanied by modification of histone $\mathrm{H} 3$ acetylation $(31,48)$. In this study, we showed that pomalidomide increases $\gamma$-globin mRNA and decreases $\beta$-globin mRNA after 3 days of erythroid differentiation (Figures $3 \mathrm{~A}$ and $5 \mathrm{~B}$ ). These changes correlated with modulation of transcription rates due to increased and decreased RNA pol II bind-
$\mathrm{K} 14$ at the $\gamma$-globin promoter. This effect appeared to be specific, since no effect on the global levels of $\mathrm{H} 3$ acetylation in cells was found (Figure 4, A and C). The mechanism of how this occurs is not clearly understood. However, it could be due to a regulation of the recruitment of coactivator and corepressor complexes. Interestingly, the chromatin organization of different HS (i.e., increased level of HS2 and HS3 acetylation) within the LCR has been reported to be differentially modulated during erythroid differentiation of hematopoietic progenitor cells (31). The analysis of histone modification at 2 different HS (HS2, HS3) showed that pomalidomide induced a decrease of acetylated histone H3 on HS2 and HS3 during erythroid maturation, supporting the observation that erythroid cells differ-
A

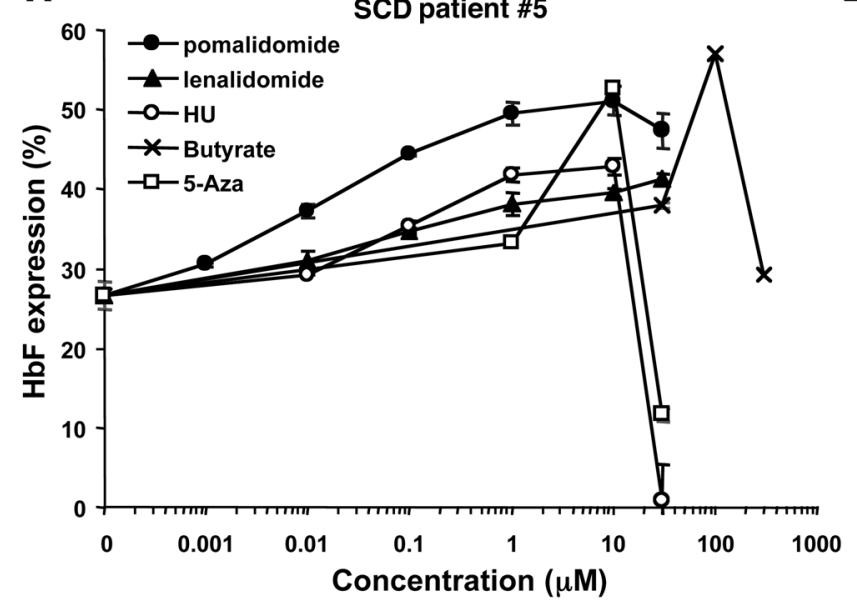

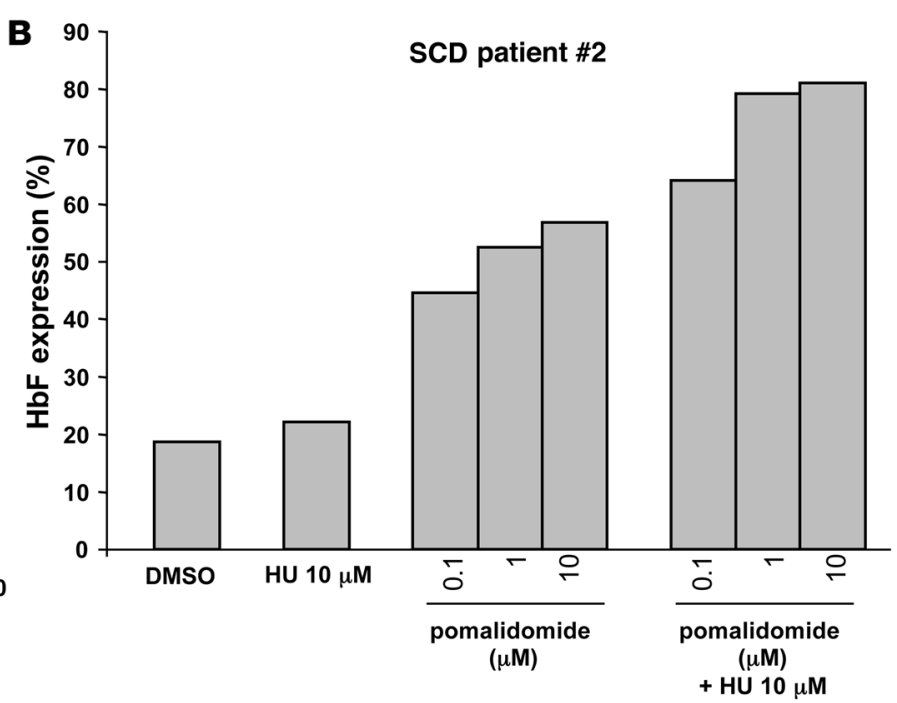

Figure 7

Effect of pomalidomide, lenalidomide, and other $\mathrm{HbF}$ inducers on $\mathrm{HbF}$ expression during erythroid differentiation of $\mathrm{CD} 34^{+}$cells from SCD patients. CD $34^{+}$cells were isolated from the PBMCs of SCD patients, expanded for 6 days, and differentiated to the erythroid lineage. (A) Expression of $\mathrm{HbF}$ was monitored by flow cytometry after 6 days of erythroid differentiation in the presence of increasing concentrations of pomalidomide, lenalidomide, $\mathrm{HU}$, butyrate, and 5-azacytidine (SCD patient no. 5 is represented). Values represent mean \pm SEM $(n=3)$. (B) Histograms of the percentage of cells expressing $\mathrm{HbF}$ in response to single or combination treatment with $\mathrm{HU}$ and pomalidomide from SCD patient no. 2 are represented. The experiments were repeated on samples from at least 2 different donors with similar results. 
entiated in the presence of pomalidomide are less mature. These observations suggest that epigenetic changes taking place during erythroid differentiation are modulated by certain IMiD immunomodulatory drugs and can explain, at least in part, the reactivation of $\gamma$-globin gene expression in human erythroid cells.

Strong epidemiological and clinical evidence that higher $\mathrm{HbF}$ levels and a pancellular distribution of $\mathrm{HbF}$ ameliorate clinical complications of SCD has provided a solid rationale for the development of new inducers of $\operatorname{HbF}(55,56)$. Other moderating factors in conjunction with $\mathrm{HbF}$ determine the beneficial effect of $\mathrm{HU}$ in SCD; the effect of HU on neutrophil counts may limit the extent of tissue destruction and pain during vasoocclusive events, underlying that both factors, increase in $\mathrm{HbF}$ levels and decrease of leukocytosis, have a role in lowering the crisis rate in SCD. To support the potential of pomalidomide as a new drug for SCD, we confirmed the strong induction of $\mathrm{HbF}$ in erythroid progenitor cells obtained from the peripheral blood of patients with SCD. Moreover, the combination of pomalidomide with HU at suboptimal noncytotoxic concentrations was synergistic in increasing the level of HbF. Pomalidomide as a monotherapy and/or combination therapy with HU in SCD could minimize toxicity arising from unnecessary dose escalation of HU.

Our results support the hypothesis that pomalidomide, alone or in combination with current approved therapies, can augment $\mathrm{HbF}$ synthesis, increasing the ratio of $\mathrm{HbF}$ to $\mathrm{HbA}$, and restore effective erythropoiesis. In addition, pomalidomide has the ability to inhibit TNF- $\alpha$ production and other inflammatory cytokines and could help reduce the chronic inflammation in sickle-cell patients, thus reducing or preventing clinical complications associated with SCD. This work suggests that pomalidomide represents a novel drug worthy of additional study for SCD and $\beta$ thalassemia and perhaps certain other diseases associated with ineffective erythropoiesis.

\section{Methods}

Materials. Pomalidomide and lenalidomide (Celgene Corp.) were dissolved in DMSO (final concentration, 0.1\%). HU, 5-azacytidine, and sodium butyrate were purchased from Sigma-Aldrich. All controls contained $0.1 \%$ of DMSO and are referred as vehicle control. CD34-PE, CD36-FITC, CD71FITC, CD235a-PE, and HbF-PE antibodies were from BD Biosciences Pharmingen. HbA-FITC antibody was purchased from PerkinElmer (Wallac). The growth factors SCF, Epo, Flt3-L, and IL-3 were purchased from Biosource International. Drug-respective $\mathrm{EC}_{50}$ was calculated from concentration-response curve, with $\mathrm{HbF} \mathrm{EC}_{50}$ defined as the log concentration of the drug that induces $50 \%$ of the maximal response (maximal response was defined by pomalidomide percentage of $\mathrm{HbF}$ expression at $10 \mu \mathrm{M}$ ).

Cell culture. BM CD $34^{+}$cells were purchased from Cambrex. Peripheral blood samples were collected from patients with SCD undergoing routine venipuncture or monthly red cell exchange after obtaining their informed consent. Collection of blood from SCD patients was approved by the Institutional Review Board of Loma Linda University Medical Center. SCD $\mathrm{CD} 34^{+}$cells, obtained from patients, were purified using Ficoll-Paque (GE Healthcare) and CD $34^{+}$microbeads (Miltenyi Biotec) according to the manufacturers' instructions. $\mathrm{BM}$ and $\mathrm{SCD} \mathrm{CD} 34^{+}$cells were cultured in Iscove's MDM with BIT 95000 (StemCell Technologies) in the presence of growth factors. Cells were differentiated toward the erythroid lineage using a 2-phase liquid culture model. During the first 6 days (first phase), CD $34^{+}$ cells were expanded with SCF (100 ng/ml), Flt3-L (100 ng/ml), and IL-3 (20 $\mathrm{ng} / \mathrm{ml})$. Expanded cells were then committed and differentiated toward the erythroid lineage (second phase) with Epo $(2 \mathrm{U} / \mathrm{ml})$ and SCF $(50 \mathrm{ng} / \mathrm{ml})$ in the presence of the indicated concentration of drugs. $\mathrm{BM} \mathrm{CD} 34^{+}$cells were used in all experiments with healthy donors. Peripheral blood CD $34^{+}$cells were used in all experiments with patients with SCD.

Flow cytometry: phenotypic characterization of the cells. At different times of erythroid differentiation, the expression of cell-surface antigens was analyzed by flow cytometry (FACSaria; BD Biosciences - Pharmingen). Cells were processed for double staining $\left(30\right.$ minutes at $\left.4^{\circ} \mathrm{C}\right)$ using FITC- and PEconjugated monoclonal antibodies. Antibodies used were CD34-PE, CD36FITC, CD71-FITC, and CD235a-PE from BD Biosciences - Pharmingen.

Flow cytometry: immunofluorescence staining for $\mathrm{HbF}$ and $\mathrm{HbA}$. Cells were washed with PBS, fixed with $2 \%$ paraformaldehyde, permeabilized with cytopermeafix (BD Biosciences - Pharmingen), stained with HbF-PE (BD Biosciences - Pharmingen) and HbA-FITC (PerkinElmer), and analyzed by flow cytometry (FACSaria or FACSArray; BD Biosciences - Pharmingen) and FlowJo cytometry software (Tree Star).

Cell viability. Cell count and viability of erythroid cells were determined after 6 days of erythroid differentiation according to Guava ViaCount reagent protocol and software (Guava Technologies).

ELISA. Hb production in erythroid cells was measured by ELISA using a human $\mathrm{Hb}$ ELISA quantitation kit from Bethyl Laboratories. In brief, cells were harvested after 6 days of erythroid differentiation, and quantitative measure of $\mathrm{Hb}$ production was determined by sandwich ELISA using anti$\mathrm{Hb}$ antibodies according to the manufacturer's instruction.

Real-time PCR. At the indicated times, total RNAs were purified from CD34+-derived erythroid cells using RNeasy Kit (QIAGEN). Reverse-transcription PCR from $100 \mathrm{ng}$ total RNA was performed using the Superscript III One-Step Quantitative PCR Reagent System (Invitrogen) and Taqman PCR probes specific for the gene of interest (Applied Biosystems) according to standard methods. The quantity of product obtained was calculated using the standard curve predetermined and normalized to $\beta$ actin.

RNA pol II ChIP assays. ChIP assays were carried out by Genpathway Inc., as described in Labhart et al. (57). G $\gamma$ globin, A $\gamma$ globin, and $\beta$ genes were assayed for their levels of transcription using Genpathway's TranscriptionPath Query assay. Chromatin was immunoprecipitated using anti-RNA pol II (Abcam) and then quantified by quantitative real-time PCR (Q-PCR) reactions containing SYBR Green (Bio-Rad). Experimental Q-PCR values were expressed relative to a DNA standard curve and were also normalized against values obtained using input (unprecipitated) DNA and the same primer sets and to the values obtained with GAPDH primer sets. Error bars represent SDs calculated from triplicate Q-PCR determinations.

Acetyl H3 K9 and K14 ChIP assays. The modification of histone $\mathrm{H} 3$ acetylation was assayed using Genpathway's FactorPath Query assay. Assays were carried out as described for TranscriptionPath, except immunoprecipitation was carried out using the acetyl H3 K9 and K14 antibody (Santa Cruz Biotechnology Inc.) and primers used were chosen in the proximal promoter regions of G $\gamma$ globin, $\beta, H S 3$, and HS2.

Isolation of histones. Cells $\left(5 \times 10^{6}\right)$ were harvested by centrifugation at $2000 \mathrm{~g}$ for 5 minutes at $4^{\circ} \mathrm{C}$, washed twice with cold PBS, resuspended in $1 \mathrm{ml}$ lysis buffer (10 mM Tris- $\mathrm{HCl}, \mathrm{pH} 6.5,50 \mathrm{mM}$ sodium bisulfite, $10 \mathrm{mM} \mathrm{MgCl} 2,10 \mathrm{mM}$ sodium butyrate, $8.6 \%$ sucrose, $1 \%$ Triton X-100) and homogenized in a Dounce homogenizer. Nuclei were isolated by centrifugation at $1000 \mathrm{~g}$ for 5 minutes at $4{ }^{\circ} \mathrm{C}$ and the pellet washed with 500 $\mu \mathrm{l}$ of suspension buffer (10 mM Tris- $\mathrm{HCl}, \mathrm{pH} 8.0,13 \mathrm{mM}$ EDTA). The pellet was then resuspended in $125 \mu \mathrm{l}$ ice-cold, sterile, distilled water, and histones were extracted from the nuclei with the addition of sulfuric acid to a final concentration of $0.4 \mathrm{~N}$ for 1 hour in ice. Insoluble particles were removed by centrifugation at $10,000 \mathrm{~g}$ for 5 minutes at $4^{\circ} \mathrm{C}$. Histones were precipitated from the supernatant with addition of $10 \mathrm{vol}$ of acetone, placed at $-20^{\circ} \mathrm{C}$ overnight, and collected by centrifugation at $10,000 \mathrm{~g}$ for 5 minutes at $4^{\circ} \mathrm{C}$. Pellets were dried using a vacuum and resuspended with $30 \mu \mathrm{l}$ of water. 
Western blot analysis of histone $\mathrm{H} 3$ acetylation. $10 \mu \mathrm{g}$ of histones were separated on 4\%-20\% Tris-Glycine gel (Invitrogen) and blotted onto nitrocellulose membrane. The membrane was incubated with acetylated histone $\mathrm{H} 3 \mathrm{~K} 9$ and $\mathrm{K} 14$ antibody and visualized using an ECL kit (GE Healthcare) following the manufacturer's protocol. The membrane was then stripped and blotted with histone $\mathrm{H} 3$ antibody.

Statistics. Comparison between different parameters evaluated in this study and vehicle controls were made by the 2 -tailed unpaired Student's $t$ test, assuming that the variance of the drug and vehicle control may be different. $P<0.05$ was considered significant, and $P<0.001$ was considered very significant.

1. Brittenham, G.M., Schechter, A.N., and Noguchi, C.T. 1985. Hemoglobin S polymerization: primary determinant of the hemolytic and clinical severity of the sickling syndromes. Blood. 65:183-189.

2. Platt, O.S., et al. 1991. Pain in sickle cell disease. Rates and risk factors. N. Engl. J. Med. 325:11-16.

3. Platt, O.S., et al. 1994. Mortality in sickle cell disease. Life expectancy and risk factors for early death. N. Engl. J. Med. 330:1639-1644.

4. Wood, W.G., Weatherall, D.J., and Clegg, J.B. 1976. Interaction of heterocellular hereditary persistence of foetal haemoglobin with beta thalassaemia and sickle cell anaemia. Nature. 264:247-249.

5. Charache, S., et al. 1995. Effect of hydroxyurea on the frequency of painful crises in sickle cell anemia. Investigators of the Multicenter Study of Hydroxyurea in Sickle Cell Anemia. N. Engl. J. Med. 332:1317-1322.

6. Platt, O.S., et al. 1984. Hydroxyurea enhances fetal hemoglobin production in sickle cell anemia. J. Clin. Invest. 74:652-656.

7. Candido, E.P., Reeves, R., and Davie, J.R. 1978. Sodium butyrate inhibits histone deacetylation in cultured cells. Cell. 14:105-113.

8. Atweh, G.F., et al. 1999. Sustained induction of fetal hemoglobin by pulse butyrate therapy in sickle cell disease. Blood. 93:1790-1797.

9. Stamatoyannopoulos, G. 2005. Control of globin gene expression during development and erythroid differentiation. Exp. Hematol. 33:259-271.

10. DeSimone, J., et al. 2002. Maintenance of elevated fetal hemoglobin levels by decitabine during dose interval treatment of sickle cell anemia. Blood. 99:3905-3908.

11. Koshy, M., et al. 2000. 2-deoxy 5-azacytidine and fetal hemoglobin induction in sickle cell anemia. Blood. 96:2379-2384.

12. Saunthararajah, Y., et al. 2003. Effects of 5-aza2'-deoxycytidine on fetal hemoglobin levels, red cell adhesion, and hematopoietic differentiation in patients with sickle cell disease. Blood. 102:3865-3870.

13. Steinberg, M.H., et al. 2003. Effect of hydroxyurea on mortality and morbidity in adult sickle cell anemia: risks and benefits up to 9 years of treatment. JAMA. 289:1645-1651.

14. Bakanay, S.M., et al. 2005. Mortality in sickle cell patients on hydroxyurea therapy. Blood. 105:545-547.

15. Fucharoen, S., et al. 1996. Hydroxyurea increases hemoglobin F levels and improves the effectiveness of erythropoiesis in beta-thalassemia/hemoglobin E disease. Blood. 87:887-892.

16. Loukopoulos, D., et al. 1998. Hydroxyurea therapy in thalassemia. Ann. N. Y. Acad. Sci. 850:120-128.

17. Perrine, S.P., et al. 1993. A short-term trial of butyrate to stimulate fetal-globin-gene expression in the beta-globin disorders. N. Engl. J. Med. 328:81-86.

18. Corral, L.G., et al. 1999. Differential cytokine modulation and $\mathrm{T}$ cell activation by two distinct classes of thalidomide analogues that are potent inhibitors of TNF-alpha. J. Immunol. 163:380-386.

19. Corral, L.G., et al. 1996. Selection of novel analogs of thalidomide with enhanced tumor necrosis factor alpha inhibitory activity. Mol. Med. 2:506-515.

20. Muller, G.W., et al. 1999. Amino-substituted thalidomide analogs: potent inhibitors of TNF-alpha production. Bioorg. Med. Chem. Lett. 9:1625-1630.

21. List, A., et al. 2006. Lenalidomide in the myelodysplastic syndrome with chromosome $5 \mathrm{q}$ deletion. N. Engl. J. Med. 355:1456-1465.

22. List, A., et al. 2005. Efficacy of lenalidomide in myelodysplastic syndromes. N. Engl. J. Med. 352:549-557.

23. Schey, S.A., et al. 2004. Phase I study of an immunomodulatory thalidomide analog, CC-4047, in relapsed or refractory multiple myeloma. J. Clin. Oncol. 22:3269-3276.

24. Loken, M.R., Shah, V.O., Dattilio, K.L., and Civin, C.I. 1987. Flow cytometric analysis of human bone marrow: I. Normal erythroid development. Blood. 69:255-263.

25. De Maria, R., et al. 1999. Apoptotic role of Fas/Fas ligand system in the regulation of erythropoiesis. Blood. 93:796-803.

26. De Maria, R., et al. 1999. Negative regulation of erythropoiesis by caspase-mediated cleavage of GATA-1. Nature. 401:489-493.

27. Zamai, L., et al. 2004. In vitro apoptotic cell death during erythroid differentiation. Apoptosis. 9:235-246.

28. Sandoval, J., et al. 2004. RNAPol-ChIP: a novel application of chromatin immunoprecipitation to the analysis of real-time gene transcription. Nucleic Acids Res. 32:e88.

29. Charache, S., et al. 1983. Treatment of sickle cell anemia with 5-azacytidine results in increased fetal hemoglobin production and is associated with nonrandom hypomethylation of DNA around the gamma-delta-beta-globin gene complex. Proc. Natl. Acad. Sci. U. S. A. 80:4842-4846.

30. DeSimone, J., Heller, P., Hall, L., and Zwiers, D. 1982. 5-Azacytidine stimulates fetal hemoglobin synthesis in anemic baboons. Proc. Natl. Acad. Sci. U. S. A. 79:4428-4431.

31. Bottardi, S., Aumont, A., Grosveld, F., and Milot, E. 2003. Developmental stage-specific epigenetic control of human beta-globin gene expression is potentiated in hematopoietic progenitor cells prior to their transcriptional activation. Blood. 102:3989-3997.

32. Cokic, V.P., et al. 2003. Hydroxyurea induces fetal hemoglobin by the nitric oxide-dependent activation of soluble guanylyl cyclase. J. Clin. Invest. 111:231-239.

33. Charache, S. 1997. Mechanism of action of hydroxyurea in the management of sickle cell anemia in adults. Semin. Hematol. 34:15-21.

34. Fibach, E., and Rachmilewitz, E.A. 1993. The twostep liquid culture: a novel procedure for studying maturation of human normal and pathological erythroid precursors. Stem Cells. 11(Suppl. 1):36-41.

35. Panzenbock, B., Bartunek, P., Mapara, M.Y., and Zenke, M. 1998. Growth and differentiation of human stem cell factor/erythropoietin-dependent erythroid progenitor cells in vitro. Blood. 92:3658-3668.
36. Neildez-Nguyen, T.M., et al. 2002. Human erythroid cells produced ex vivo at large scale differentiate into red blood cells in vivo. Nat. Biotechnol. 20:467-472.

37. Wojda, U., Noel, P., and Miller, J.L. 2002. Fetal and adult hemoglobin production during adult erythropoiesis: coordinate expression correlates with cell proliferation. Blood. 99:3005-3013.

38. Bohmer, R.M., Campbell, T.A., and Bianchi, D.W. 2000. Selectively increased growth of fetal hemoglobin-expressing adult erythroid progenitors after brief treatment of early progenitors with transforming growth factor beta. Blood. 95:2967-2974.

39. Reinhardt, D., et al. 1998. Hemoglobin F in myelodysplastic syndrome. Ann. Hematol. 76:135-138.

40. Nagel, R.L., et al. 1979. Structural bases of the inhibitory effects of hemoglobin F and hemoglobin A2 on the polymerization of hemoglobin S. Proc. Natl. Acad. Sci. U. S. A. 76:670-672.

41. Verhelle, D., et al. 2007. Lenalidomide and CC-4047 inhibit the proliferation of malignant $B$ cells while expanding normal CD34+ progenitor cells. Cancer Res. 67:746-755.

42. Knight, R. 2005. IMiDs: a novel class of immunomodulators. Semin. Oncol. 32:S24-S30.

43. Fathallah, H., Sutton, M., and Atweh, G.F. 2005. Pharmacological induction of fetal hemoglobin: why haven't we been more successful in thalassemia? Ann. N. Y. Acad. Sci. 1054:228-237.

44. Yuan, J., et al. 1993. Accelerated programmed cell death (apoptosis) in erythroid precursors of patients with severe beta-thalassemia (Cooley's anemia). Blood. 82:374-377.

45. Bank, A. 2006. Regulation of human fetal hemoglobin: new players, new complexities. Blood. 107:435-443.

46. Patrinos, G.P., et al. 2004. Multiple interactions between regulatory regions are required to stabilize an active chromatin hub. Genes Dev. 18:1495-1509.

47. Vakoc, C.R., et al. 2005. Proximity among distant regulatory elements at the beta-globin locus requires GATA-1 and FOG-1. Mol. Cell. 17:453-462.

48. Schubeler, D., et al. 2000. Nuclear localization and histone acetylation: a pathway for chromatin opening and transcriptional activation of the human beta-globin locus. Genes Dev. 14:940-950.

49. Traeger-Synodinos, J., et al. 1996. The triplicated alpha-globin gene locus in beta-thalassaemia heterozygotes: clinical, haematological, biosynthetic and molecular studies. Br. J. Haematol. 95:467-471.

50. Camaschella, C., et al. 1997. Different hematological phenotypes caused by the interaction of triplicated alpha-globin genes and heterozygous betathalassemia. Am. J. Hematol. 55:83-88.

51. Winichagoon, P., Fucharoen, S., Thonglairoam, V., and Wasi, P. 1987. Different severity of homozygous beta-thalassemia among siblings. Hum. Genet. 76:296-297.

52. Cao, H., Stamatoyannopoulos, G., and Jung, M. 2004. Induction of human gamma globin gene expression by histone deacetylase inhibitors. Blood. 103:701-709.

53. Johnson, J., et al. 2005. Fetal hemoglobin induction 
by the histone deacetylase inhibitor, scriptaid. Cell. Mol. Biol. (Noisy-le-grand) 51:229-238

54. Witt, O., et al. 2003. Induction of fetal hemoglobin expression by the histone deacetylase inhibitor apicidin. Blood. 101:2001-2007.

55. Noguchi, C.T., Rodgers, G.P., Serjeant, G., and
Schechter, A.N. 1988. Levels of fetal hemoglobin necessary for treatment of sickle cell disease. N. Engl. J. Med. 318:96-99.

56. Conley, C.L., Weatherall, D.J., Richardson, S.N., Shepard, M.K., and Charache, S. 1963. Hereditary persistence of fetal hemoglobin: a study of 79 affected persons in 15 Negro families in Baltimore. Blood. 21:261-281.

57. Labhart, P., et al. 2005. Identification of target genes in breast cancer cells directly regulated by the SRC-3/AIB1 coactivator. Proc. Natl. Acad. Sci. U. S. A. 102:1339-1344. 